\title{
Intravitreal versus Posterior Subtenon Injection of Triamcinolone Acetonide for Diabetic Macular Edema
}

\author{
Young Jae Choi, MD, In Kyung Oh, MD, Jae Ryung Oh, MD, PhD, Kuhl Huh, MD, PhD \\ Department of Ophthalmology, Korea University College of Medicine, Seoul, Korea
}

\begin{abstract}
Purpose: To compare the short-term effects of intravitreal versus posterior subtenon injection of triamcinolone acetonide for diabetic macular edema.

Methods: This is a prospective and interventional study. Sixty eyes of 60 patients who had diffuse diabetic macular edema were assigned to receive a single intravitreal injection $(4 \mathrm{mg})$ or a single posterior subtenon injection $(40 \mathrm{mg})$ of triamcinolone acetonide. The central retinal thickness was measured using optical coherent tomography before injection and at 1 and 3 months after injection. Visual acuity and intraocular pressure (IOP) were also measured.

Results: Both intravitreal and posterior subtenon injections of triamcinolone acetonide resulted in significant improvements in visual acuity at 1 month and 3 months after injection. Both groups resulted in a significant decrease in central macular thickness (CMT) at 1 month and 3 months post-injection. IOP in the intravitreal injection group was significantly higher than in the posterior subtenon injection group at 3 months after injection.

Conclusions: The posterior subtenon injection of triamcinolone acetonide had a comparable effect to the intravitreal triamcinolone injection and showed a lower risk of elevated IOP. Posterior subtenon injection of triamcinolone acetonide may be a good alternative for the treatment of diffuse diabetic macular edema. Korean Journal of Ophthalmology 20(4):205-209, 2006
\end{abstract}

Key Words: Diffuse diabetic macular edema, Intravitreal injection, Posterior subtenon injection, Triamcinolone acetonide

Diabetic macular edema is a common cause of visual loss in patients with diabetic retinopathy. It may occur by focal leakage from microaneurysms, which is often associated with intraretinal lipid deposition in a circinate pattern, and by diffuse leakage from the perifoveal retinal capillaries. In the Early Treatment Diabetic Retinopathy Study (ETDRS), focal laser photocoagulation was applied for leakages from the microaneurysms and grid laser photocoagulation was applied for areas of diffuse capillary leakage. ${ }^{1,2}$ However, several studies have shown that eyes with diffuse macular edema carry a particularly poor prognosis despite laser photocoagulation. ${ }^{3,4}$ In the ETDRS, ${ }^{1}$ only $17 \%$ of the eyes had any improvement in visual acuity and less than $3 \%$ had a visual improvement of 3 or more ETDRS lines.

In recent years, the intravitreal administration of triamcinolone acetonide has provided promising results for the treat-

Received: March 31, 2006 Accepted: November 15, 2006

Reprint requests to Jaeryung Oh, MD, PhD. Department of Ophthalmology, Korea University College of Medicine, \#126-1 Anam-dong 5-ga, Sungbuk-gu, Seoul 136-705, Korea. Tel: 82-2-920-5521, Fax: 82-2-924-6820, E-mail: ojr4991@yahoo.co.kr

* This study was presented in part at the 94th Annual meeting of the Korean Ophthalmological Society, October 2005. ment of diffuse macular edema. ${ }^{5-9}$ However, the risk of ocular complications such as intraocular pressure (IOP) elevation, ${ }^{10-12}$ endophthalmitis, ${ }^{13}$ retinal detachment and glaucoma was reported.

Posterior subtenon injection of a steroid is an alternative method with proven effectiveness in various ocular diseases like cystoid macular edema and intermediate uveitis. Posterior subtenon injection of triamcinolone has also been reported to be an effective and safe treatment for diffuse diabetic macular edema. ${ }^{14}$

We performed a prospective study to compare effectiveness and safety between intravitreal and posterior subtenon injection of triamcinolone acetonide for the treatment of diffuse macular edema.

\section{Materials and Methods}

Sixty eyes of 60 patients with macular edema involving the fovea were enrolled in this study. Diffuse macular edema was defined by central thickening on a biomicroscopy using a 90-diopter noncontact lens and by diffuse fluorescein leakage on fluorescein angiography. Central macular thickness (CMT) was required to be $>250 \mu \mathrm{m}$ on an optical coherent tomography (OCT). Patients with other pathologies 
of macula or optic disc such as glaucoma or ocular hypertension were excluded. Patients with extensive foveal ischemia with more than one disc diameter of capillary closure on fluorescein angiography were excluded. Patients who had undergone intraocular surgery or macular grid laser photocoagulation within 3 months prior to the injection were excluded.

One of the authors (K.H.) performed intravitreal injection and another (J.O.) performed posterior subtenon injection during the same period. The physicians who checked visual acuity, IOP and CMT had not been informed of the purpose of this study or the assignment schedule.

Intravitreal injection was done under sterile conditions in the operating room. Eyes receiving the intravitreal injection were anesthetized by topical instillation of $0.5 \%$ proparacaine hydrochloride. Under the operating microscope, $0.1 \mathrm{ml}$ of triamcinolone acetonide $(4 \mathrm{mg})$ was injected slowly via a 30 gauge needle through the pars plana, $3.0 \mathrm{~mm}$ posterior to the limbus in the pseudopakic eyes and $4.0 \mathrm{~mm}$ posterior to the limbus in phakic eyes. For the posterior subtenon injection, under topical anesthesia ( $0.5 \%$ proparacaine hydrochloride), a small incision ( $8 \mathrm{~mm}$ posterior to the limbus) was made through the superotemporal forniceal conjunctiva and tenon's capsule to bare the sclera using Westcott scissors. The curved portion of the pinpoint cannula was inserted and a volume of $1 \mathrm{ml}$ containing $40 \mathrm{mg}$ triamcinolone was slowly injected behind the eye through the incision site. After the triamcinolone application was completed, the cannula was withdrawn slowly, with gentle pressure maintained by a sterile swab along the path of the cannula. No drug reflux was observed.

The patients were evaluated on the basis of central retinal thickness from OCT, visual acuity and IOP. All the patients underwent these examinations before injection and at 1 week, 1 month and 3 months post-injection. During the OCT procedure, each eye underwent six radial scans centered on the fovea. The value which printed on the OCT automated mode determined the central retinal thickness. The best-corrected visual acuity on the decimal charts was examined at each visit and was converted to the logarithm of minimal angle of resolution $(\log M A R)$ scale for statistical analysis. The IOP was measured using Goldmann applanation tonometry and the number of glaucoma medications used was recorded.

The temporal changes in logMAR visual acuity, central retinal thickness and IOP were compared using the Wilcoxon signed rank test. The differences between groups in logMAR visual acuity, central retinal thickness, IOP and other continuous variables were compared using the Mann-Whitney $U$ test.

\section{Results}

The mean age of the patients $( \pm \mathrm{SD})$ was $60.69 \pm 10.8$ years, with a range of 46 to 70 years. The mean $( \pm \mathrm{SD})$ duration of diabetes was $16.3 \pm 8.1$ years (range, 4-30 years). Patient demographics are shown in Table 1. No statistically significant differences were found between groups regarding age, gender, the ratio of left to right eyes, the ratio of PDR to NPDR or DM duration.

Table 1. Patient Characteristics

\begin{tabular}{lccc}
\hline & IVTA $^{*}$ & PSBTA $^{\dagger}$ & p value \\
\hline No. of eyes & 30 & 30 & - \\
Mean Age & $60.09 \pm 10.8$ & $60.89 \pm 8.1$ & 0.362 \\
Gender (male / female) & $11 / 19$ & $9 / 21$ & 0.520 \\
Right / Left & $12 / 18$ & $14 / 16$ & 0.398 \\
PDR / NPDR & $17 / 13$ & $17 / 13$ & 0.561 \\
Phakic / Pseudophakic & $23 / 7$ & $22 / 8$ & 0.505 \\
DM duration (mean) & 11.7 & 13.4 & 0.477 \\
\hline
\end{tabular}

*IVTA: intravitreal triamcinolone injection group, ${ }^{\dagger}$ PSBTA: posterior subtenon triamcinolone injection group.

Visual Acuity Change

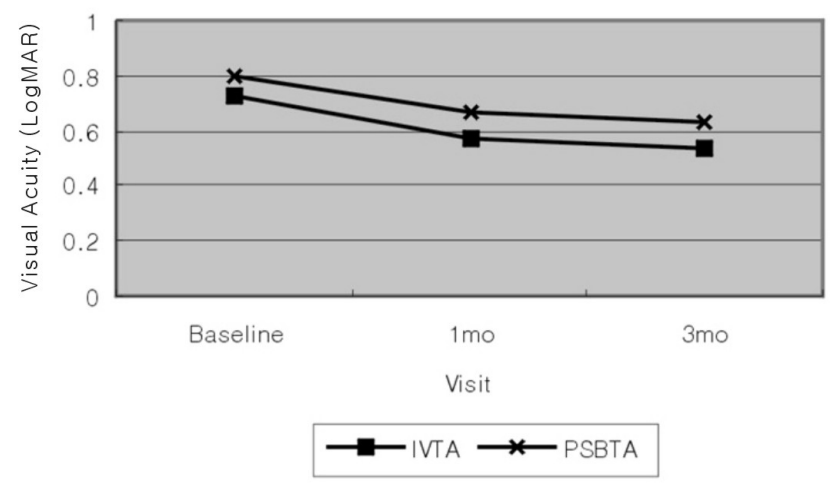

Fig. 1. Visual acuity in the intravitreal and posterior sub-tenon injected eyes at baseline and at 1 and 3 months after triamcinolone acetonide injection.

Table 2. Visual Acuity (LogMAR)

\begin{tabular}{|c|c|c|c|c|c|}
\hline & \multicolumn{2}{|c|}{ IVTA* } & \multicolumn{2}{|c|}{$\mathrm{PSBTA}^{\dagger}$} & \multirow{2}{*}{$\begin{array}{c}\text { between two groups } \\
\mathrm{p} \text { value }\end{array}$} \\
\hline & Mean \pm SD & $\mathrm{p}$ value & Mean \pm SD & $\mathrm{p}$ value & \\
\hline Baseline & $0.731 \pm 0.406$ & & $0.788 \pm 0.280$ & & 0.338 \\
\hline POD $1 \mathrm{mo}$ & $0.571 \pm 0.393$ & 0.001 & $0.650 \pm 0.281$ & 0.011 & 0.672 \\
\hline POD $3 \mathrm{mo}$ & $0.535 \pm 0.382$ & 0.001 & $0.623 \pm 0.264$ & 0.007 & 0.461 \\
\hline
\end{tabular}

*IVTA: intravitreal triamcinolone injection group, ${ }^{\dagger}$ PSBTA: posterior subtenon triamcinolone injection group. 
Table 3. Central Macular Thickness $(\mu \mathrm{m})$

\begin{tabular}{|c|c|c|c|c|c|}
\hline & \multicolumn{2}{|c|}{ IVTA* } & \multicolumn{2}{|c|}{$\mathrm{PSBTA}^{\dagger}$} & \multirow{2}{*}{$\begin{array}{c}\text { between two groups } \\
\text { p value }\end{array}$} \\
\hline & Mean \pm SD & $\mathrm{p}$ value & Mean \pm SD & $\mathrm{p}$ value & \\
\hline Baseline & $428.3 \pm 125.4$ & & $480.0 \pm 1235.4$ & & 0.461 \\
\hline POD $1 \mathrm{mo}$ & $256.5 \pm 56.0$ & 0.046 & $318.4 \pm 136.5$ & 0.043 & 0.273 \\
\hline POD $3 \mathrm{mo}$ & $230.6 \pm 60.7$ & 0.036 & $271.1 \pm 89.8$ & 0.026 & 0.795 \\
\hline
\end{tabular}

*IVTA: intravitreal triamcinolone injection group, ${ }^{\dagger} \mathrm{PSBTA}$ : posterior subtenon triamcinolone injection group.

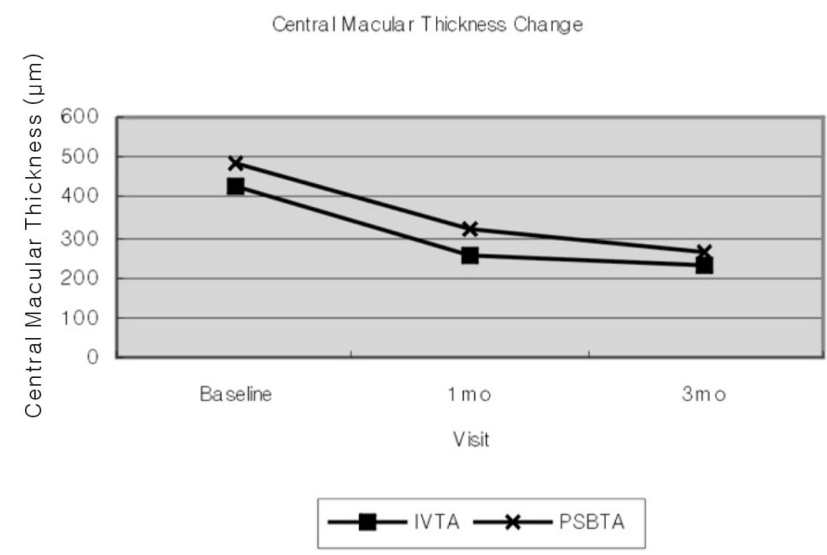

Fig. 2. Central macular thickness in the intravitreal and posterior subtenon injected eyes at baseline and at 1 and 3 months after triamcinolone acetonide injection.
The mean $( \pm \mathrm{SD})$ visual acuity before triamcinolone acetonide injection and at 1 week, 1 month and 3 months thereafter is shown in Table 2 and Fig. 1. The mean baseline visual acuity was not significantly different between the 2 groups $(\mathrm{p}=0.338)$. In both groups, the visual acuity significantly improved throughout the study. In the intravitreal injection group, the mean visual acuity at 1 month $(0.571 \pm 0.393$; p $=0.001)$ and 3 months $(0.535 \pm 0.382 ; \mathrm{p}=0.001)$ after the injection were significantly better than baseline measurements. In the posterior subtenon injection group, the mean visual acuity at 1 month $(0.650 \pm 0.281 ; \mathrm{p}=0.011)$ and 3 months $(0.623 \pm 0.264 ; \mathrm{p}=0.007)$ after the injection was also significantly better than the baseline measurements. Between the 2 groups, there were no significant differences in the mean visual acuity changes before injection or at 1 month and 3 months after injection.

The mean baseline CMT was not significantly different

\section{B}

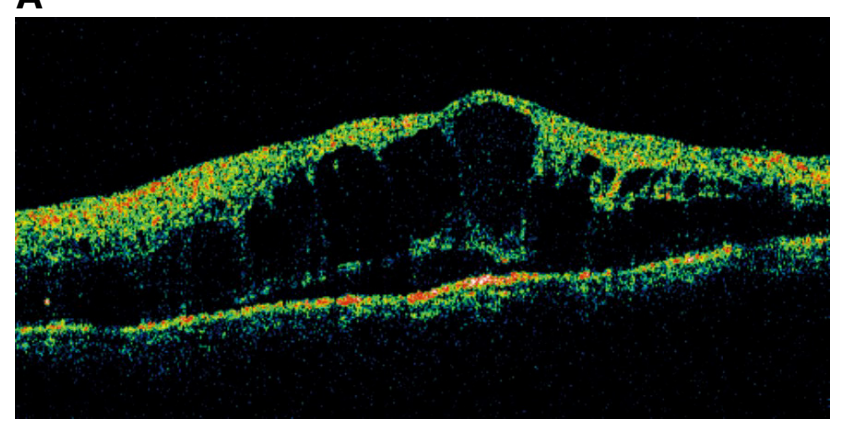

C

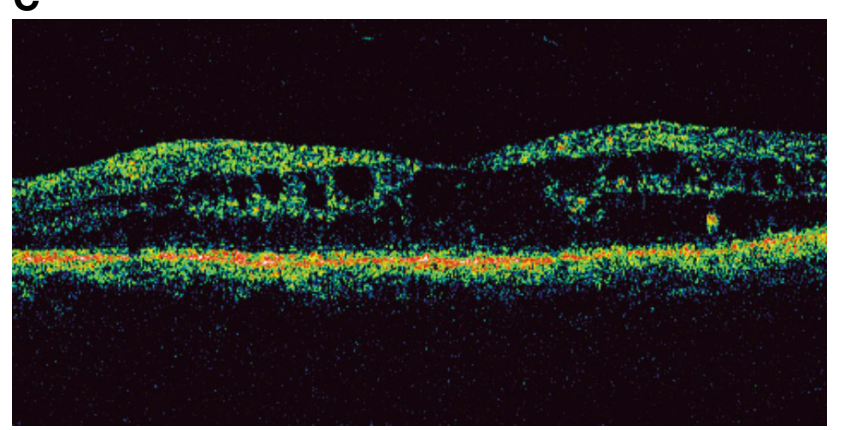

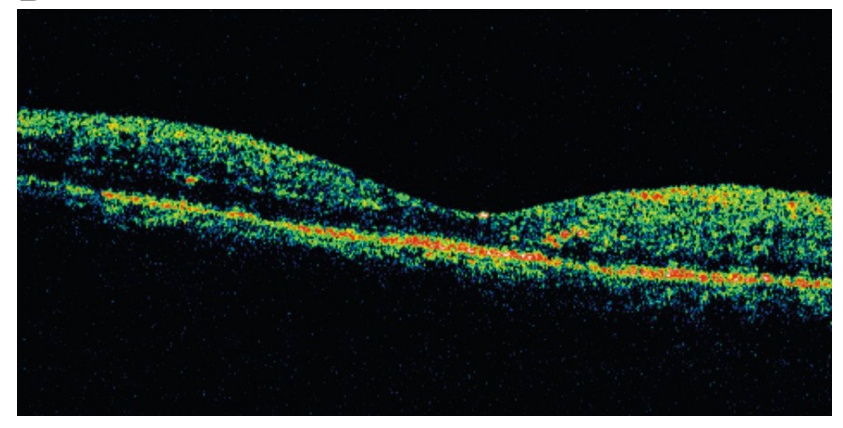

D

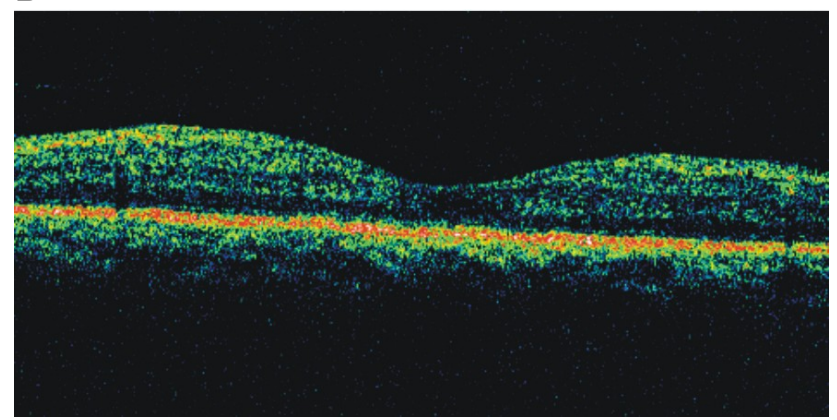

Fig. 3. Changes in the OCT images of representative patient in the intravitreal and posterior subtenon injection groups. In an eye that underwent intravitreal injection, the marked macular edema (A) decreased substantially and the eye showed virtually normal macular configuration at 3 months (B) after injection. In an eye that underwent posterior subtenon injection, the macular edema (C) also decreased substantially with time, and the eye showed virtually normal macular configuration at 3 months (D) after injection. 
Table 4. Intraocular Pressure $(\mathrm{mmHg})$

\begin{tabular}{|c|c|c|c|c|c|}
\hline & \multicolumn{2}{|c|}{ IVTA* } & \multicolumn{2}{|c|}{$\mathrm{PSBTA}^{\dagger}$} & \multirow{2}{*}{$\begin{array}{c}\text { between two groups } \\
\text { p value }\end{array}$} \\
\hline & Mean \pm SD & $\mathrm{p}$ value & Mean \pm SD & $\mathrm{p}$ value & \\
\hline Baseline & $16.36 \pm 2.17$ & & $16.46 \pm 2.04$ & & 0.524 \\
\hline POD 1 wk & $16.00 \pm 2.76$ & 0.513 & $16.48 \pm 2.01$ & 0.497 & 0.323 \\
\hline POD $1 \mathrm{mo}$ & $17.80 \pm 3.47$ & 0.229 & $16.76 \pm 2.28$ & 0.527 & 0.362 \\
\hline POD $3 \mathrm{mo}$ & $18.44 \pm 3.76$ & 0.072 & $16.28 \pm 2.23$ & 0.292 & 0.026 \\
\hline
\end{tabular}

*IVTA: intravitreal triamcinolone injection group, ${ }^{\dagger}$ PSBTA: posterior subtenon triamcinolone injection group.

IOP Change

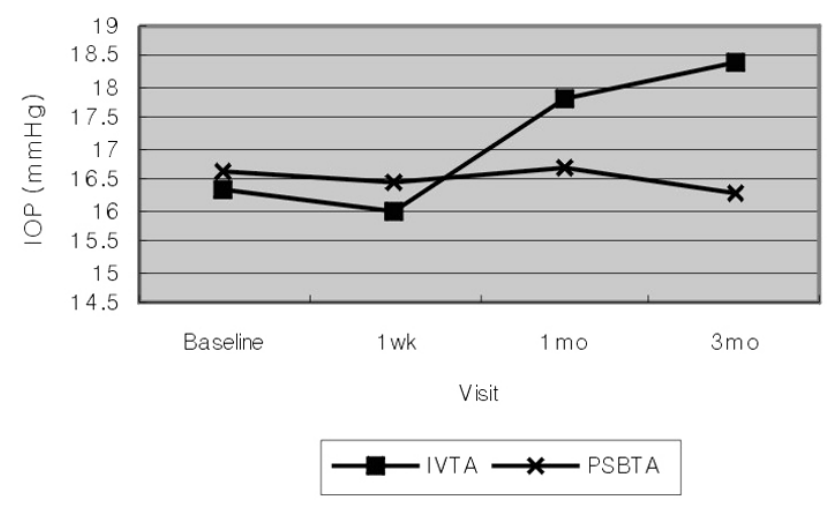

Fig. 4. Intraocular pressure in the intravitreal and posterior subtenon injected eyes at baseline and at 1 and 3 months after triamcinolone acetonide injection.

between the 2 groups $(\mathrm{p}=0.461)$. In both the intravitreal and posterior subtenon injection group, the CMT was significantly decreased through the study (Table 3, Fig. 2). At 3 months after injection, OCT demonstrated a reduction of the mean CMT (intravitreal group: $46.2 \%$, subtenon group: $43.5 \%$ ). Between the 2 groups, there was no significant difference in the mean CMT change before injection or at 1 month and 3 months after injection. Fig. 3 illustrates the changes in the OCT images of a representative patient in the intravitreal injection group and of a patient in the posterior subtenon injection group.

The mean baseline IOP did not show differences between the 2 groups $(\mathrm{p}=0.524)$. In the intravitreal injection group, IOP tended to rise after the injection although the change was not statistically significant (Table 4, Fig. 4). Ten eyes (33\%) experienced an IOP elevation to $21 \mathrm{mmHg}$ or higher during the follow-up period. In the posterior subtenon injection group, a temporal change of IOP was not found. Only 1 eye (3.3\%) experienced an IOP of $21 \mathrm{mmHg}$ or higher during the follow up period. At 3 months after injection, the IOP change of the intravitreal injected eyes was greater than that of the posterior subtenon capsule injected eyes $(\mathrm{p}=0.026)$.

\section{Discussion}

This study demonstrates that intravitreal injection or posterior subtenon injection has a beneficial effect in reducing the diabetic macular edema. Two groups did not show any significant difference in visual acuity or mean CMT thickness improvement after injection.

In this study, the change of mean visual acuity (LogMAR) after intravitreal injection was $0.160(21.8 \%)$ at 1 month and $0.196(26.8 \%)$ at 3 months after the injection. The change of mean CMT was $171.6 \mu \mathrm{m}(40.1 \%)$ at 1 month and $197.7 \mu \mathrm{m}$ $(46.2 \%)$ at 3 months after intravitreal injection. These results were similar to previous studies. Martidis et al. ${ }^{5}$ reported that CMT decreased by 55\% and 57.5\% at 1 and 3 months after intravitreal trimcinolone injection, respectively. Ciardella et al. $^{8}$ reported decreases of $42 \%$ and $46.4 \%$. Jonas et al. ${ }^{9}$ reported that visual acuity(LogMAR) improved by 0.15 $(15.3 \%)$ and $0.19(19.3 \%)$ at 1 and 3 months after intravitreal trimcinolone injection, respectively.

Posterior subtenon injection of triamcinolone has been used with proven effectiveness in conditions with a breakdown in the blood-retinal barrier, such as cystoid macular edema and intermediate uveitis. Recently, Ohguro et al. ${ }^{14}$ reported an observational case series indicating the effectiveness of posterior subtenon triamcinolone infusion in diffuse diabetic macular edema in eyes that had not responded to vitrectomy. Bakri et al. ${ }^{15}$ also reported that visual acuities remained stable or improved over a 12-month period after posterior subtenon triamcinolone injections for refractory diabetic macular edema. These recent results have a general connection with our study.

Freeman et al. ${ }^{16}$ have shown by ultrasound B-scan that the superotemporal placement technique results in more accurate placement of steroids near the macula. Geroski et al. ${ }^{17}$ reported the usefulness of the transscleral pathway in delivering the drug to the retina. Weijtens et al. ${ }^{18}$ reported that the intravitreal concentration of the steroid increased after its peribulbar injection. On the basis of these reports, it can be summarized that the injected triamcinolone is located on the subtenon macular area and its therapeutic concentration on the choroids or retina can be obtained through the transscleral pathway.

Cardillo et al. ${ }^{19}$ compared intravitreal injection with posterior subtenon injection of triamcinolone in diabetic macular edema. They concluded that the intravitreal injection was more favorable than the posterior subtenon injection for the 
anatomic and functional aspects of improvement. Bonini-Filho et al. ${ }^{20}$ also suggested that intravitreal injection may be more effective than posterior subtenon injection for the management of refractive diffuse diabetic macular edema. These two studies differ from our results in that our study show that both intravitreal and posterior subtenon injections may be equally tolerated with a short-term performance. The study of Cardillo et al was informative in that two approaches were performed to each eye of the same patient with bilateral symmetric diffuse macular edema. However one limitation of the study was the relatively small sample size (12 patients). In Bonini-Filho et al's study, the patients had refractive diabetic macular edema. Thus, their results cannot directly be compared to our results.

One advantages of posterior subtenon administration is a lower risk of complication. IOP elevation is the most common complication after intravitreal triamcinolone injection..$^{10-12}$ Although not statistically significant, IOP after intravitreal injection tended to rise in our study. At 3 months after injection, the change of IOP in the intravitreal injection group was greater than that of the posterior subtenon injection group. Other complications such as endophthalmitis and retinal detachment were also reported following intravitreal injection in other studies.

In conclusion, the short-term efficacy of the intravitreal injection and of the posterior subtenon injection of triamcinolone in diffuse diabetic macular edema was similar. The posterior subtenon injection was less invasive and safer than the intravitreal injection. Therefore, posterior subtenon injection of triamcinolone acetonide may be a good option for the treatment of diffuse diabetic macular edema.

\section{References}

1. Early Treatment Diabetic Retinopathy Study Research Group. Photocoagulation for diabetic macular edema. Early Treatment Diabetic Retinopathy Study report number 1. Arch Ophthalmol 1985;103:1796-806.

2. Early Treatment Diabetic Retinopathy Study Research Group. Treatment techniques and clinical guidelines for photocoagulation of diabetic macular edema. Early Treatment Diabetic Retinopathy Study report number 2. Ophthalmology 1987; 94:761-74.

3. Lee CM, Olk RJ. Modified grid laser photocoagulation for diffuse macular oedema: long-term visual results. Ophthalmology 1991;98:1594-602.

4. Early Treatment Diabetic Retinopathy Study Research Group. Focal photocoagulation treatment of diabetic macular edema. Relationship of treatment effect to fluorescein angiographic and other retinal characteristics at baseline: ETDRS report no.19. Arch Ophthalmol 1995;113:1144-55.

5. Martidis A, Duker JS, Greenberg PB, et al. Intravitreal Triamcinolone for Refractory Diabetic Macular Edema. Ophthalmology 2002;109:920-27.

6. Massin P, Audren F, Haouchine B, et al. Intravitreal Triamcinolone Acetonide for Diabetic Diffuse Macular Edema; Preliminary Results of a Prospective Controlled Trial. Ophthalmology 2004;111:218-25

7. Karacorlu M, Ozdemir H, Karacorlu S, et al. Intravitreal triamcinolone as a primary therapy in diabetic macular oedema. Eye 2004;19:382-6.

8. Ciardella AP, Klancnik J, Schiff W, et al. Intravitreal triamcinolone for the treatment of refractory diabetic macular oedema with hard exudates: an optical coherence tomography study. Br J Ophthalmol 2004;88:1131-6.

9. Jonas JB, Akkoyun I, Kreissig I, et al. Diffuse diabetic macular oedema treated by intravitreal triamcinolone acetonide: a comparative, non-randomised study. $\mathrm{Br} J$ Ophthalmol 2005;89:321-6.

10. Jonas JB, Degenring RF, Kreissig I, et al. Intraocular Pressure Elevation after Intravitreal Triamcinolone Acetonide Injection. Ophthalmology 2005;112:593-8.

11. Smithen LM, Ober MD, Maranan L, et al. Intravitreal Triamcinolone Acetonide and Intraocular Pressure. Am J Ophthalmol 2004;138:740-3.

12. Park HY, Yi K, Kim HK. Intraocular pressure elevation after intravitreal triamcinolone acetonide injection. Korean $J$ Ophthalmol 2005;19:122-7.

13. Moshfeghi DM, Kaiser PK, Scott IU, et al. Acute Endophthalmitis Following Intravitreal Triamcinolone Acetonide Injection. Am J Ophthalmol 2003;136:791-6.

14. Ohguro N, Okada AA, Tano Y. Trans-Tenon's retrobulbar triamcinolone infusion for diffuse diabetic macular edema. Graefes Arch Clin Exp Ophthalmol 2004;242:444-5.

15. Bakri SJ, Kaiser PK. Posterior Subtenon Triamcinolone Acetonide for Refractory Diabetic Macular Edema. Am J Ophthalmol 2005;139:290-4.

16. Freeman WR, Green RL, Smith RE. Echographic localization of corticosteroids after periocular injection. $\mathrm{Am} \mathrm{J}$ Ophthalmol 1987;130:281-8.

17. Geroski DH, Edelhauser HF. Transscleral drug delivery for posterior segment disease. Adv Drug Deliv Rev 2001;52: $37-48$.

18. Weijtens O, van der Sluijs FA, Schoemaker RC, et al. Peribulbar corticosteroid injection: vitreal and serum concentrations after dexamethasone disodium phosphate injection. Am J Ophthalmol 1997;123:358-63.

19. Cardillo JA, Melo LA Jr, Costa RA, et al. Comparison of Intravitreal versus Posterior Sub-Tenon's Capsule Injection of Triamcinolone Acetonide for Diffuse Diabetic Macular Edema. Ophthalmology 2005;112:1557-63.

20. Bonini-Filho MA, Jorge R, Barbosa JC, et al. Intravitreal Injection Versus Sub-Tenon's Infusion of Triamcinolone Acetonide for Refractory Diabetic Macular Edema: A Randomized Clinical Trial. Invest Ophthalmol Vis Sci 2005;46:3845-9. 